\title{
Utilization of Geospatial Network Analysis Technique for Optimal Route Planning During COVID-19 Pandemic
}

\author{
Pravin Kokane, Mohd. Ammar Ashraf and Vinita Shinkar
}

\begin{abstract}
The local government bodies (LGBs) in India have taken several steps to reduce the spread of the virus. Disinfection of common public spaces such as roads and streets are one such step adopted by municipal council of Basmat city after lock down from March 2020. Basmat city is a ' $B$ ' class municipal council with 80,000 population located in Hingoli district of Maharashtra, India. The spraying of Sodium Hypochlorite ( $\mathrm{NaClO}$ ) solution on roads and government establishments with the help of firefighting services is a novel as well as cost effective responsive measure as per guidelines of the central government of India. This chapter aims to analyze the efficiency of disinfection with the help of Network Analysis tools in Arc GIS. Various components such as shortest route analysis for refilling the tanks and analysis of various impedance factors such as time-cost analysis and route tracking form an integral part of the study. In addition to this, the availability of stock and consumption pattern of disinfectant are also analyzed. This research focuses on the attributes of distance traversed, cost of fuel and labor and time taken for sanitization vehicles at service stops. The results are evident that with the use of geospatial technology, all the attributes have reduced values as compared to the previous situation.
\end{abstract}

\subsection{Introduction}

Since the outbreak of the novel coronavirus in 2019, a substantial amount of research has been carried out to address the inter-relationship between technological advancements and the pandemic. The research particularly deals with the spatial aspect of the COVID-19 outbreak and analyzing the use of Geographical Information Systems (GIS) as a tool for providing effective measures in containment of the outbreak. Geographic tracking of spatial features enables us to keep a record of the entities and GIS offers multiple tools for spatial accounting. Recent advancements in Geographic Information Systems, has provided with improved decision making about a location. Spatial analytics and location intelligence are the key aspects which make GIS beneficial for improved geographic recording of assets. GIS enables for effective communication in the form of visualizations and maps by better understanding of geographical attributes.

The multidisciplinary nature of GIS technology means that the diffusion, appropriation and use of GIS technologies are distributed in a variety of subject domains and its application in day to day problems of human beings [1]. GIS applications has covered a varied range of sectors including health geography, cultural and anthropological geography, transportation, and land dynamics. 
Many researches have studied the spatial aspect of diseases in purview of its nature and behavior with respect to a geographical area. The most famous paradigm of early medical geography was Dr. John Snow, considered to be the father of modern epidemiology, who demonstrated the water-borne origin of cholera by plotting cholera-related deaths in London during the most severe 1854 epidemic on maps [2]. Disease maps have been used since historic times and with GIS it is now possible to keep a track of diseases in a digital format.

Considering the wide range of analysis tools offered by GIS, the spatial aspect of COVID-19 can be analyzed comprehensively with them. Recent technical features of GIS such as location intelligence and live tracking have made it possible for COVID-19 to be potentially mapped and understand the spread of the outbreak. Features such as temporal analysis have aided in understanding the timely spread of the disease. This research particularly focuses on the utilization of network analysis feature of Arc GIS in decision making for the Municipal authorities. The network analysis toolset has been linked with the spraying of disinfectants in municipal areas. To contain the spread of the outbreak, disinfecting public places such as public buildings, major and minor roadways with Sodium Hypochlorite $(\mathrm{NaClO})$ solution is undertaken by the municipal authorities of multiple Indian cities. As per the Central Government of India, spraying of disinfectants has been mandated in Indian cities to avoid the virus from sustaining at public places.

Spraying of disinfectants over large urban areas involve attributes such as cost and time on account of Government officials. This makes it important to utilize modern technologies that can aid the decision-making abilities of the officials. The purpose of this research is to utilize the potential of geospatial technology in order to aid the Municipal authority officials of Basmat City to reduce the cost and time required to spray the disinfectant using the Vehicle Routing Problem (VRP) for devising the optimal paths for fire-fighting vehicles.

\subsection{Literature Review}

In this section, the literature reviewed in accordance with the network analysis tools in GIS is presented. Utilization of GIS for effective healthcare planning is presented in many studies across the world. A study by [3] presents the use of network analysis in developing a GIS based emergency response system for Delhi, India. The study focuses on integrating real time traffic data with the existing transportation network. Optimal route planning was used to analyze the best route for reaching the emergency site by avoiding congested routes. Network analysis attributes such as shortest path analysis, Origin destination survey and proximity analysis were deployed for building the emergency response system. In another study by [4] the practicality of the shortest path analysis tool in GIS is improved. The Dijkstra's Algorithm which is the principle that works at the backend of the shortest path analysis is optimized by changing the starting node with the search process. This enables to maintain the nodes using a stack structure to avoid revisiting the nodes. In this case, the real time traffic information is not considered.

Another relevant study carried out for Ghana region by [5] is also based on emergency response service by the firefighting services. This service was developed for the Ghana National Fire Services (GNFS) in the metropolis of Kumasi where the GNFS can take better decisions. The optimal route planning in case of a fire incident in the metropolis was devised by considering model attributes such as slope of the roads, travel distance and time and the delays in travel time. Optimal route planning for determining effective evacuation methods in San Diego is performed by [6]. In this study, GIS network analysis is used for public issuing of evacuation orders in case of emergency situations by using 2007 Wildfire datasets. An Origin-Destination (OD) ranking model was deployed to determine evacuation routes between affected areas and nearest shelters. Multiple road features and land-based attributes were considered while building the OD model.

Advancement in the geospatial technologies have upgraded the GIS tools and services. GIS packages are now being introduced in the market with better spatial analysis capabilities. Services and complex businesses involving fieet of vehicles with multiple orders, stops, restrictions, using roadside utilities need a solution to avoid scaled cost in the process of transportation. These issues 
are now the things of the past since the introduction of network analyst toolset in the ArcGIS platform. Vehicle Routing Problem (VRP) is one such tool in the package, which can find the best route for a single vehicle to visit many stops (for delivering order or for servicing at the stop). The primary goal of these kinds of analysis is to reduce the transportation time and reduce the overall operating cost. VRP can used to solve much complex problems, involving multiple vehicles with multiple capacities and matching vehicles capacity with order quantities, multiple vehicles with special tools and matching their service capabilities, giving breaks to drivers, pairing multiple orders so the same route delivers them.

\subsection{Methodology and Materials}

The following section presents the detailed methodology that was followed to conduct this research. The methodology fiowchart depicts the steps that are performed using Arc GIS 10.2 software. The data preparation includes digitizing road vector layer using Open Street Map (OSM) and satellite imagery from Google Earth. The administrative boundary of ward map has been obtained from the municipal council of Basmat city. The major public government buildings and landmarks have been located from ground verification and satellite imagery. Following this, the georeferencing process of municipal boundary map has been performed, and the geodatabase has been created.

After the data preparation, the network layers have been created. The network layers include the service stops of spraying the disinfectant. The attributes such as road name, design speed of the road, road type, length of the road and time taken for the fire-fighting vehicle to traverse the road have all been updated in the network layers. Further, the network topology and network dataset have been created. Finally, the vehicle routing problem for the firefighting services to spray the disinfectant has been solved.

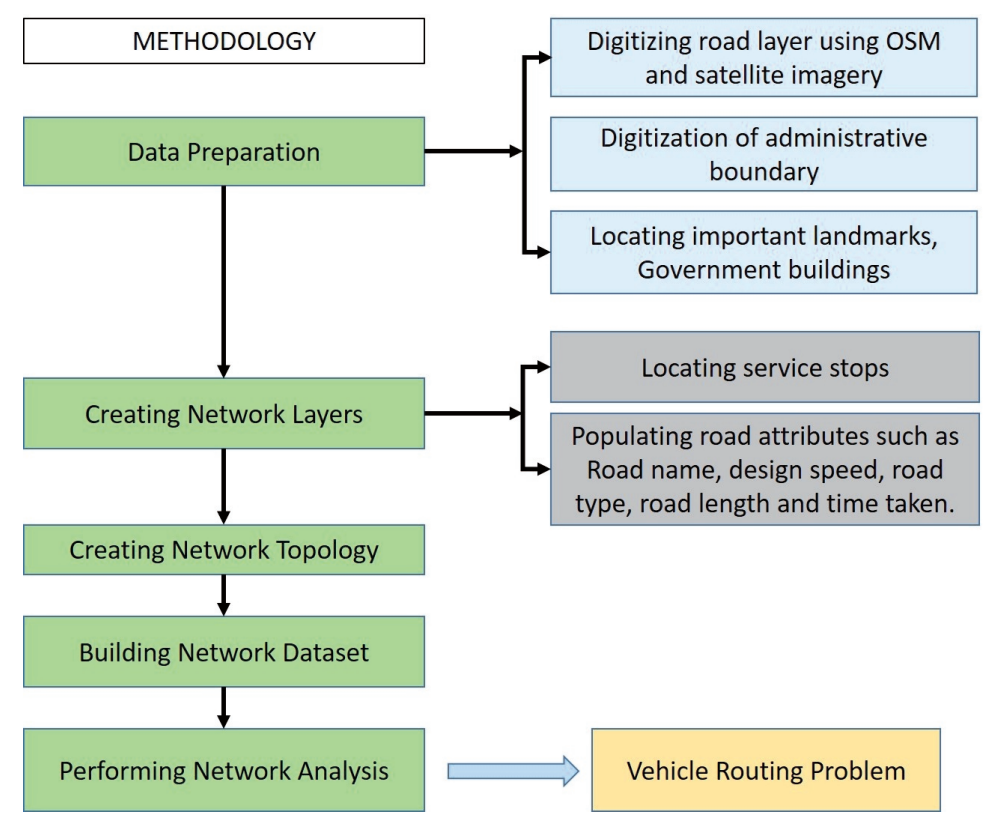

FIGURE 14.1

Methodological Framework of Study 


\subsubsection{Data Preparation}

The data preparation includes downloading the OSM network data and satellite imagery of Basmat city, preparing the network layout, and linking the attribute data. The study area is the Basmat city located in Hingoli district of the state of Maharashtra. This city is a ' $\mathrm{B}$ ' class municipal council.

The study area is extended from $19^{\circ} 33^{\prime} 02^{\prime \prime} \mathrm{N}$ to $77^{\circ} 15^{\prime} 89^{\prime \prime} \mathrm{E}$. The Basmat city area is of 12.06 sq.km with 14 ward divisions. The base map and road network data of Basmat city was downloaded from Open street map. OSM has been accessed through Arc GIS online web mapping service. The road network data has an attribute named Road name for names of the roads that have been matched with Google earth imagery. The Design speed attribute includes design speed of the roads which were assigned by taking IRC $86-1983$ as reference. The Road type attribute consists of classification of the roads according to the hierarchy which includes Arterial Roads, Sub-Arterial Roads, Collector and Local roads. The Road length attribute includes length of the roads that are calculated using calculate geometry tool.

\subsubsection{The Network Dataset}

The next step is preparing the network dataset to carry out network analysis for fire-fighting vehicles. The topology tool is deployed to remove unnecessary pseudo nodes and dangles in the network that occur during the digitization process. The road network is integrated using the Integrate tool in Data Management and other layers such as road and stops are included in the feature dataset. Further, the road name and landmarks are assigned for directional fiow of vehicles.

\subsubsection{Building the VRP Route}

After building the network dataset, the Vehicle routing problem layer is created and all the VRP layers are activated from the toolbar. The stops which are assigned for spraying of $\mathrm{NaClO}$ solution are imported for a shift of the day. The service time which is the spraying time for the fire-fighting vehicle is assigned to the stops. The spraying time data is provided by the Basmat Municipal Council. The filling stations which are the depots are the locations where the Sodium Hypochlorite $(\mathrm{NaClO})$ solution is filled in the tanks of fire-fighting vehicles. After this the routes through which the fire-fighting vehicles traverse are assigned to the route layer. The initial stop of filling station and terminating stop of filling station are assigned. The Start time of the vehicle is taken as 7 a.m. and end time is taken as 8 a.m.

\subsection{Results and Discussion}

This study presented the analysis of Vehicle Routing problem of fire fighting vehicles that are used for sanitisation to spray Sodium Hypochlorite solution. With the surge of Covid-19 cases, the sanitisation process of public buildings and was taken up by the Basmat Municipal Council. Municipality assigned this task to the sanitation department, which must be carried out in a stipulated time. Major landmarks, government buildings, major religious places, markets, colonies with symptomatic patients were identified for disinfection. Fire-fighting vehicles were assigned for transportation of sanitation workers to the service locations where disinfection was supposed to be carried out. From the ground-based questionnaire survey conducted on 28, 29 and 30 March 2020 and the recorded odometer readings, the time taken by the fire-fighting vehicles was higher as the routes taken to reach the sanitisation destinations were random. This incurred higher time and cost for the government officials being spent on the sanitisation process. The government officials expected a sound way for reducing the cost and time. To address this issue, study tried to address this issue using geospatial technology to analyse whether the cost and time spent on sanitisation process can be reduced. For the same, this study applied the Vehicle Routing Problem to the 
fire-fighting sanitisation vehicles. For this the optimal route analysis was carried out for all the routes. The optimal route analysis generates the most optimal route between two locations.

With the network analysis extension in Arc GIS, it becomes very easy to set the network parameters for optimal route analysis such as the travel time that is the impedance factor, the start time of the travel and restrictions such as road directions whether unidirectional or bidirectional. The starting point and terminating point of travel is the Sodium Hypochlorite $(\mathrm{NaClO})$ filling station.

The route for sanitization is developed such that all the locations where the service is to be provided (service locations) are visited once during the total travel. From the table 1 given below, comparison between the previous route and the optimal route is analysed based on pre-determined attributes. The three major routes are divided over the period of three days from 28th March to 30th March.

The VRP for the three major routes is given in the following maps for the three consecutive days (Figure 14.2) respectively. The odometer reading, time taken for travel by the fire-fighting vehicle, the fuel cost spent by the government officials and the labor cost are compared for the previous route taken and the optimal route taken later. It can be inferred from the readings that all the factors considered perform better in case of optimal routes. Time taken for the fire fighting vehicles, fuel cost and labor cost are all comparatively lesser in case of optimal routes when compared with the routes originally followed. The comparison is also presented in graphical format.

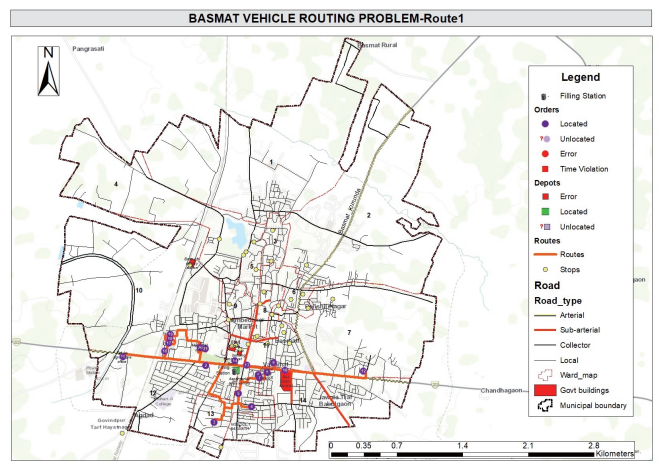

(a)

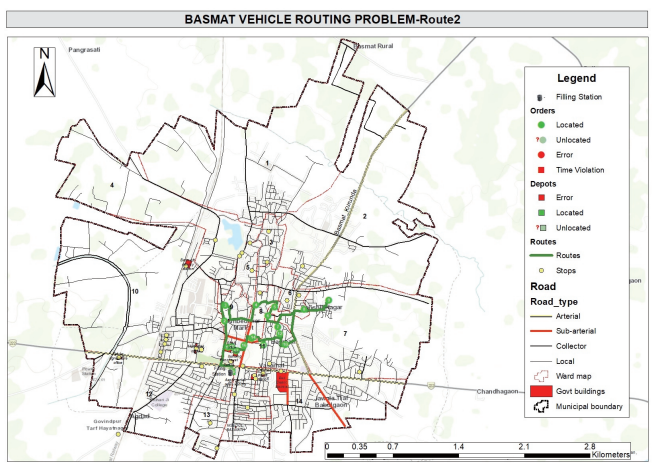

(b)

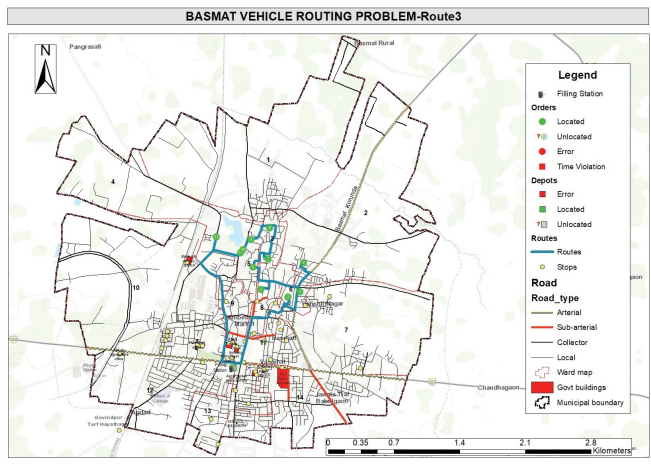

(c)

FIGURE 14.2

Basmat Vehicle Routing Problem: a) Route 1; b) Route 2; c) Route 3 
TABLE 14.1

Comparative Analysis of Attributes between Previous and Optimal Route

\begin{tabular}{|c|c|c|}
\hline Shift & $\overline{\text { Previous Route }}$ & Optimal Route \\
\hline \multirow[t]{4}{*}{ Route-1 } & Odometer reading: $11000 \mathrm{~m}$ & $\begin{array}{l}\text { Analyzed distance: } \\
9377.8 \mathrm{~m}\end{array}$ \\
\hline & Time Taken: 12 hours & $\begin{array}{l}\text { Time Taken: } 9 \text { hours } 52 \\
\text { min }\end{array}$ \\
\hline & Fuel cost: Rs.389 & Fuel cost: Rs.329 \\
\hline & Labor cost $=$ Rs. 1320 & Labor cost $=$ Rs. 1070 \\
\hline \multirow[t]{4}{*}{ Route-2 } & $\begin{array}{lll}\begin{array}{l}\text { Odometer } \\
\text { (approx.) }\end{array} & \text { reading: } & 6250 \\
\end{array}$ & $\begin{array}{l}\text { Analyzed distance: } \\
5224 \mathrm{~m}\end{array}$ \\
\hline & Time Taken: 8hrs. (approx.) & Time Taken: $7 \mathrm{hrs} .38 \mathrm{~min}$ \\
\hline & Fuel cost: Rs. 221 & Fuel cost: Rs.184 \\
\hline & Labor $\operatorname{cost}=$ Rs. 840 & Labor cost $=$ Rs. 795 \\
\hline \multirow[t]{4}{*}{ Route-3 } & $\begin{array}{lll}\text { Odometer } & \text { reading: } & 7500 \\
\text { (approx.) } & & \end{array}$ & $\begin{array}{l}\text { Analyzed distance: } 6874 \\
\mathrm{~m}\end{array}$ \\
\hline & $\begin{array}{l}\text { Time Taken: } \\
\text { (approx.) }\end{array}$ & $\begin{array}{l}\text { Time Taken: } 6 \text { hrs. } 10 \\
\text { min }\end{array}$ \\
\hline & Fuel cost: Rs.265 & Fuel cost: Rs. 240 \\
\hline & Labor $\operatorname{cost}=$ Rs. 780 & Labor cost $=$ Rs. 619 \\
\hline
\end{tabular}

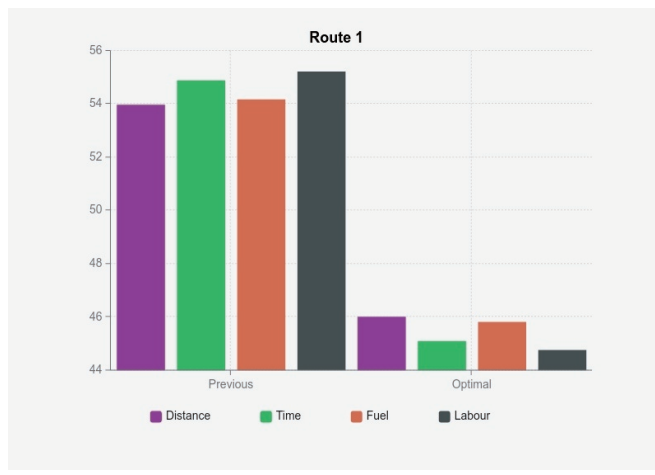

(a)

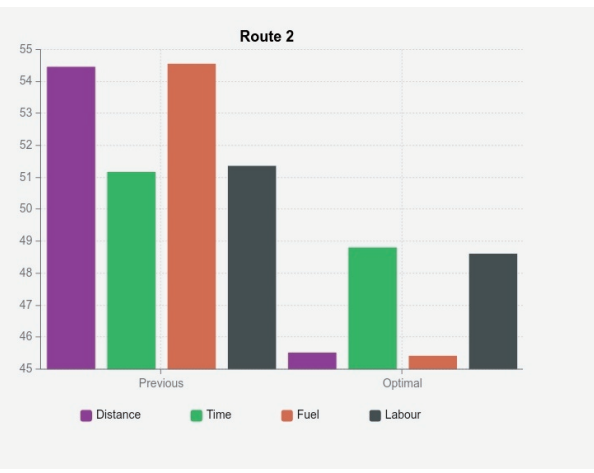

(b)

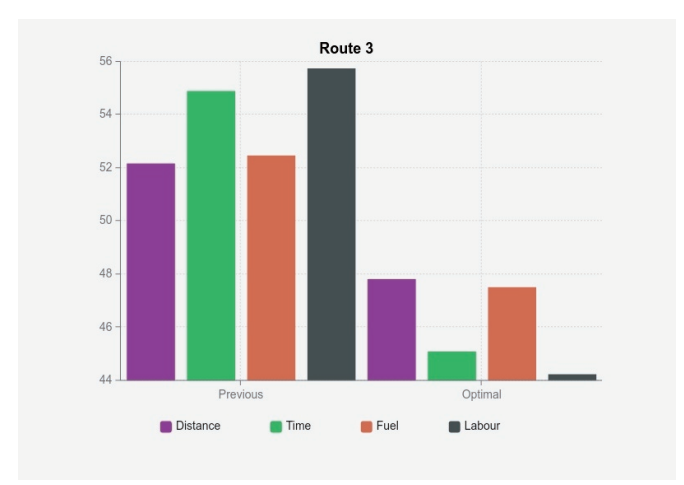

(c)

\section{FIGURE 14.3}

Comparative Analysis between attributes of: a) Route 1 in percentage; b) Route 2 in percentage; c) Route 3 in percentage 


\subsection{Conclusion}

In this research, an augmented approach of Arc GIS based network analysis using Vehicle Routing problem is applied to the Basmat city area. With the outbreak of Covid-19, sanitisation of public spaces has been made mandatory and this involves spending of huge monetary cost and time on account of government authorities. The Djikstra optimal routing algorithm in Arc GIS offers best results for network analysis. The vehicle routing problem applied in this research to find the optimal route which saves time and cost. The VRP for route 1 has reduced the travel distance and fuel cost by $8 \%$ and the travel time taken by $12 \%$. The labor cost is reduced by $10 \%$. Similarly, for route 2 , the travel distance is reduced by $8 \%$ and the travel time by $4 \%$. The labor cost is reduced by $2 \%$ and the fuel cost by $10 \%$. For VRP route 3 , the travel distance is reduced by $4 \%$ and travel time by $8 \%$. The labor cost is reduced by $4 \%$ and fuel cost by $12 \%$. After obtaining positive results with the use of network analysis, in future research this study propose to utilize geospatial technology for analyzing the attributes of cost, time and quantity of disinfectant spraying for building level data by incorporating building level information data such as height of building, size and total fioor area , material, building use etc. to predict the attributes for sanitisation automatically. Result out of such studies will help in better emergency preparedness and quick response of Urban Local Bodies (ULB's) as like Basmat.

\section{Acknowledgements}

We deeply acknowledge Mr. Ashok Sabale, Chief Officer, Basmat Muncipal Council for extending kind support and help during this project. We also thank all fire brigade personnel for their support during interview and data collection.

\section{References}

[1] Hao Ye, Michael Brown, and Jenny Harding. Gis for all: exploring the barriers and opportunities for underexploited gis applications. OSGeo Journal, 13(1):19-28, 2014.

[2] George J Musa, Po-Huang Chiang, Tyler Sylk, Rachel Bavley, William Keating, Bereketab Lakew, Hui-Chen Tsou, and Christina W Hoven. Use of gis mapping as a public health tool - from cholera to cancer. Health services insights, 6:HSI-S10471, 2013.

[3] Anshul Bhagat and Nikhil Sharma. Gis-based application for emergency preparedness and management accelerating response system through gis. In 14th Esri India User Conference, pages 1-7, 2013.

[4] Dechuan Kong, Yunjuan Liang, Xiaoqin Ma, and Lijun Zhang. Improvement and realization of dijkstra algorithm in gis of depot. In 2011 International Conference on Control, Automation and Systems Engineering (CASE), pages 1-4. IEEE, 2011.

[5] Eric K Forkuo and Jonathan A Quaye-Ballard. Gis based fire emergency response system. 2013.

[6] J Yi Carine, Roy S Park, Osamu Murao, and Eiji Okamoto. Emergency management: Building an od ranking model using gis network analysis. Journal of Disaster Research, 7(6):1, 2012. 
$\Longrightarrow$ Taylor \& Francis Taylor \& Francis Group

http://taylorandfrancis.com 